\title{
Interval modulation of recurrent slow slip events by two types of earthquake loading
}

Yuta Mitsui

\begin{abstract}
Geodetic studies have discovered recurrent spontaneous slow slip events (SSEs) at major faults. The SSE recurrence intervals should reflect stress states at the faults, including load effects of large earthquakes in neighboring areas. Here, we focus on temporal changes of the SSE recurrence intervals. We perform numerical model experiments with the rate- and state-dependent friction in a three-dimensional elastic medium to simulate the SSE recurrence interval changes by the earthquake loading effects. One result is gradual shortening of the SSE recurrence intervals owing to a nucleation process of a nearby large earthquake, as revealed by several previous studies. This effect reflects magnitude of the elastic interaction between the SSE and earthquake areas. As an example, when the distance between the SSE and earthquake areas is almost zero, a short-term rapid decrease of the SSE recurrence intervals precedes the earthquake occurrence (approximately by a decade). The other result is that external stress perturbation, as large as $0.1 \mathrm{MPa}$, can reduce the SSE recurrence intervals to a similar extent. Furthermore, the interval modulation by the stress perturbation continues for a prolonged period until the occurrence of the adjacent earthquake. Both effects may be observable, as is advancing at the Boso zone, Japan, but their separation is difficult under the present circumstances.
\end{abstract}

Keywords: Slow slip events; Recurrence interval; Elastic interaction; Numerical modeling; Rate and state friction

\section{Findings Introduction}

Development of geodetic measurements revealed the existence of spontaneous slow slip events (hereafter called SSE) at major faults (Linde et al. 1996; Hirose et al. 1999). In particular, on some subduction plate interfaces, large SSEs over Mw 6 have occurred repeatedly (e.g., Dragert et al. 2001; Ozawa et al. 2003; Dragert et al. 2004; Heki and Kataoka 2008). Their mean recurrence intervals are on the order of several months to several years.

Deviation from the mean value of the SSE recurrence intervals at each zone may reflect fluctuation of stress states on the plate interface. For example, Hirose et al. (2012) pointed out that the recurrent SSEs near the Boso Peninsula, Japan (Figure 1(a)), was likely hastened by the 2011 Tohoku-oki megathrust earthquake via static stress change. Moreover, some numerical studies with frictional systems stated the importance of elastic interaction among multiple focal areas of slip events (e.g., Kato 2004; Ariyoshi et al. 2009; Matsuzawa et al. 2010). In such frictional

Correspondence: mitsui.yuta@shizuoka.ac.jp

Department of Geosciences, Shizuoka University, 836 Ōya, Suruga-ku, Shizuoka 422-8529, Japan models, the recurrence of SSEs near a source area of a large earthquake is affected by a nucleation process of the large earthquake. Ozawa (2014) proposed that the shortening of the recurrence interval of the Boso SSE might represent the latter nucleation effect. Kato et al. (2014) showed the existence of a hidden SSE immediately after the 2011 Tohoku earthquake and suggested a complex evolution of the SSE recurrence intervals.

Focusing on this issue, we select three subduction zones for comparison: the Boso zone, the northern Cascadia zone, and the Yaeyama zone, Japan. Although there are other subduction zones with SSEs (e.g., some zones in southwest Japan, the Alaska zone, the Guerrero zone, the Costa Rica zone, et al.), the selected three zones have experienced many (not less than eight) and large (over Mw 6) SSEs. Figure 1 exhibits their locations in the Pacific-rim scale. We also show the approximate regional locations of the SSE areas and the source areas of nearby large earthquakes at the same scale by Figure 1, referring to many previous studies. The Boso SSEs occurred at the plate interface around $140.4^{\circ} \mathrm{E},-35.1^{\circ} \mathrm{N}$ (e.g., Hirose et al. 2012). The source fault of the 1923 Kanto earthquake (Mw-8 class) estimated geodetically

\section{Springer}

() 2015 Mitsui; licensee Springer. This is an Open Access article distributed under the terms of the Creative Commons Attribution License (http://creativecommons.org/licenses/by/4.0), which permits unrestricted use, distribution, and reproduction in any medium, provided the original work is properly credited. 


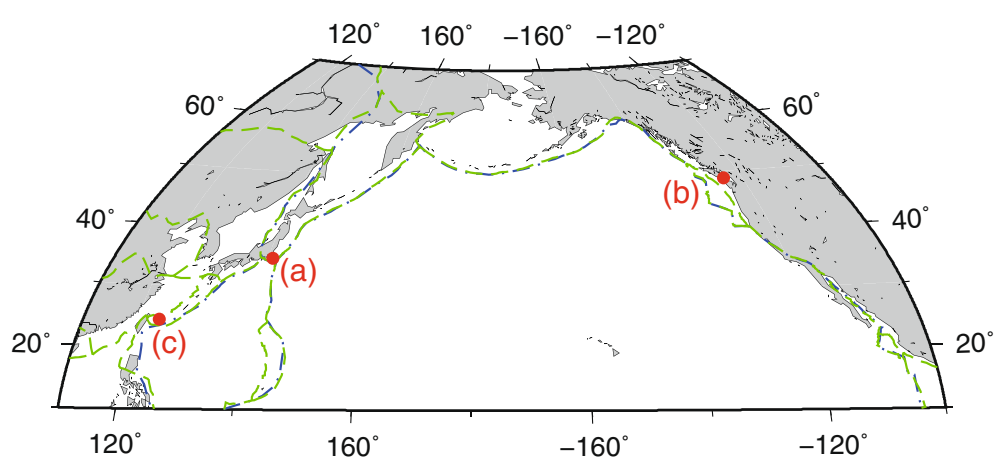

(a) Boso

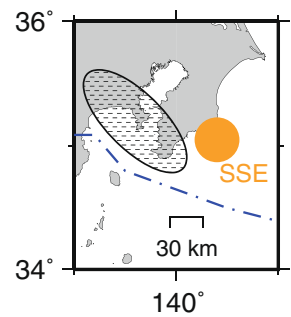

(b) N. Cascadia

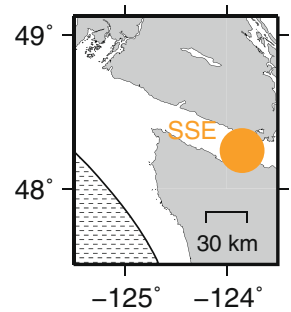

(c) Yaeyama

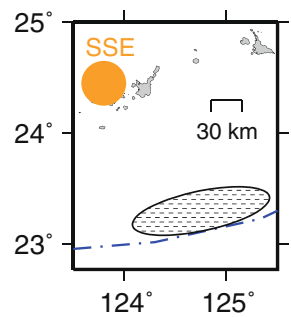

Figure 1 The upper figure displays the selected three subduction zones in the Pacific-rim scale. The blue chain lines represent the plate boundaries in the NUVEL-1 model (DeMets et al., 1990), and the green broken lines represent those in a modified model (Bird, 2003). The lower figures illustrate the approximate locations of the SSE areas (orange circles) and source areas of nearby large earthquakes (shaded ovals) at the same scale. (a) The Boso zone (Hirose et al., 2012; Ando, 1971). (b) The northern Cascadia zone (Szeliga et al., 2008; Leonard et al., 2010). (c) The Yaeyama zone (Heki and Kataoka, 2008; Nakamura, 2009a). We use Generic Mapping Tools (Wessel and Smith 1995) to draw the maps.

(Ando 1971) is located on the west side of the SSE area. At the northern Cascadia zone, the SSEs occurred in an approximate range of $124.0^{\circ} \mathrm{W}$ to $123.7^{\circ} \mathrm{W}$, and $-48.1^{\circ}$ $\mathrm{N}$ to $48.4^{\circ} \mathrm{N}$ (e.g., Rogers and Dragert 2003; Szeliga et al. 2008). The source area of the megathrust earthquakes, possibly as large as Mw 9, was estimated in the shallower part along the whole Cascadia subduction zone (e.g., Atwater 1987; Leonard et al. 2010). Beneath the Yaeyama Islands, Japan, the SSE area is located around $123.8^{\circ} \mathrm{E},-24.5^{\circ} \mathrm{N}$ (Heki and Kataoka 2008). The Yaeyama Islands had been attacked by huge tsunamis in the past thousands of years. Nakamura (2009a) proposed that the 1771 Yaeyama tsunami was caused by a large thrust (possibly interplate) earthquake of which source area was near the Ryukyu Trench.

As Figure 1 shows, the distance between the SSE and the earthquake areas at the Boso zone is shorter than those at the northern Cascadia and the Yaeyama zone. This point is assured although the estimated sources of the SSEs and the earthquakes have much uncertainty. The SSE and the earthquake areas at the Boso zone are adjacent and might overlap partly, while their distances at the other zones are on the order of $100 \mathrm{~km}$. On the other hand, the notable shortening of the SSE recurrence interval only occurred at the Boso zone (we will discuss the details in a later discussion section). This correspondence is worthy of note.
Here, we perform numerical experiments with a frictional system targeting the effects of large earthquakes on SSE recurrence intervals. We do not assume a bit complex distribution of the SSE areas as the previous studies (Ariyoshi et al. 2009; Matsuzawa et al. 2010) but set simpler models to investigate the effect of the distance between SSE and earthquake areas via the earthquake nucleation process. We further investigate the external stress perturbation effect as the 2011 Tohoku-oki earthquake for the Boso zone.

\section{Methods}

We use a frictional model with the rate- and statedependent friction law (Dieterich 1979; Ruina 1983) on a planar fault, using the aging type of the state evolution law and the radiation damping term (Rice 1993). The equation of equilibrium and the constitutive law of friction at each fault grid can be represented as:

$$
\begin{aligned}
& \tau-\left(\tau_{0}+A \ln \left(\frac{v}{v_{0}}\right)+B \ln \left(\frac{\nu_{0} \theta}{L}\right)\right)=\frac{G v}{2 c_{s}} \\
& \frac{d \theta}{d t}=1-\frac{\nu \theta}{L}
\end{aligned}
$$

where $\tau$ is the loading shear stress; $\tau_{0}$ is its steady-state value corresponding to steady slip with a reference slip velocity (equal to a plate loading rate in this study) $v_{0}$; $v$ is the slip velocity; $\theta$ is a state variable; $A, B, L$ are 
frictional parameters; and $G$ and $c_{s}$ are the elastic parameters of the rigidity and the $\mathrm{S}$-wave velocity. The parameters $A$ and $B$ are multiplication of effective normal stress and other parameters. We do not consider evolution of the effective normal stress such as thermal pressurization of pore fluid (Mitsui and Hirahara 2009) for simplicity. Thus, the frictional behavior on the fault is controlled by three parameters: $A, B$, and $L$. Qualitatively, $B-A$ value represents stress drop amount of slip event, and $L$ value represents slowness of friction change with slip. The shear stress $\tau$ on the fault is loaded by slip deficits from steady slip (Tse and Rice 1986), which is a velocity boundary condition in contrast to a stress boundary condition for plate subduction dynamics (e.g., Heki and Mitsui 2013). The change of the loading shear stress $\tau$ at grid $i\left(x_{i}, y_{i}\right)$ is given by:

$$
\begin{aligned}
\tau\left(x_{i}, y_{i}\right)= & \tau_{0}\left(x_{i}, y_{i}\right)+\sum_{x_{j}} \sum_{y_{j}} K\left(x_{i}-x_{j}, y_{i}-y_{j}\right) \\
& \times\left[v_{0} t-u\left(x_{j}, y_{j}\right)\right]
\end{aligned}
$$

where $t$ is the time and $u$ is the slip amount. The stiffness kernel $K$ in the three-dimensional elastic full space is described by some preceding studies (e.g., Kato 2003).
We simultaneously solved the above equations in the Fourier domain (e.g., Kato 2003). Thus, artificial periodic boundary conditions are introduced on the four sides of the model fault. To reduce their effects, we set steady-slip zones around the four sides. The procedure for numerical integration is following our previous work (Mitsui and Hirahara 2011).

We set one oval SSE area, one oval earthquake area, and the other intermediate zone to calculate the occurrence of the SSEs and the earthquakes interacting with each other. As shown in Figure 2, we compare a long-distance model (model 1), a short-distance model (model 2), and a zerodistance model (model 3) in terms of the distance between the SSE area and the earthquake area. The calculation results show limit-cycle behavior or some close to it after the disappearance of the initial condition effects.

The frictional parameters in the SSE area are $A=$ $0.03 \mathrm{MPa}, B=0.045 \mathrm{MPa}$, and $L=0.8 \mathrm{~cm}$; those in the earthquake area are $A=3 \mathrm{MPa}, B=4.5 \mathrm{MPa}$, and $L=$ $20 \mathrm{~cm}$; and those in the intermediate zone are $A=0.9 \mathrm{MPa}$, $B=0.3 \mathrm{MPa}$, and $L=20 \mathrm{~cm}$. The parameter values more or less followed some previous numerical studies (e.g., Kato 2004). Note that only the $L$ values for mimicking actual
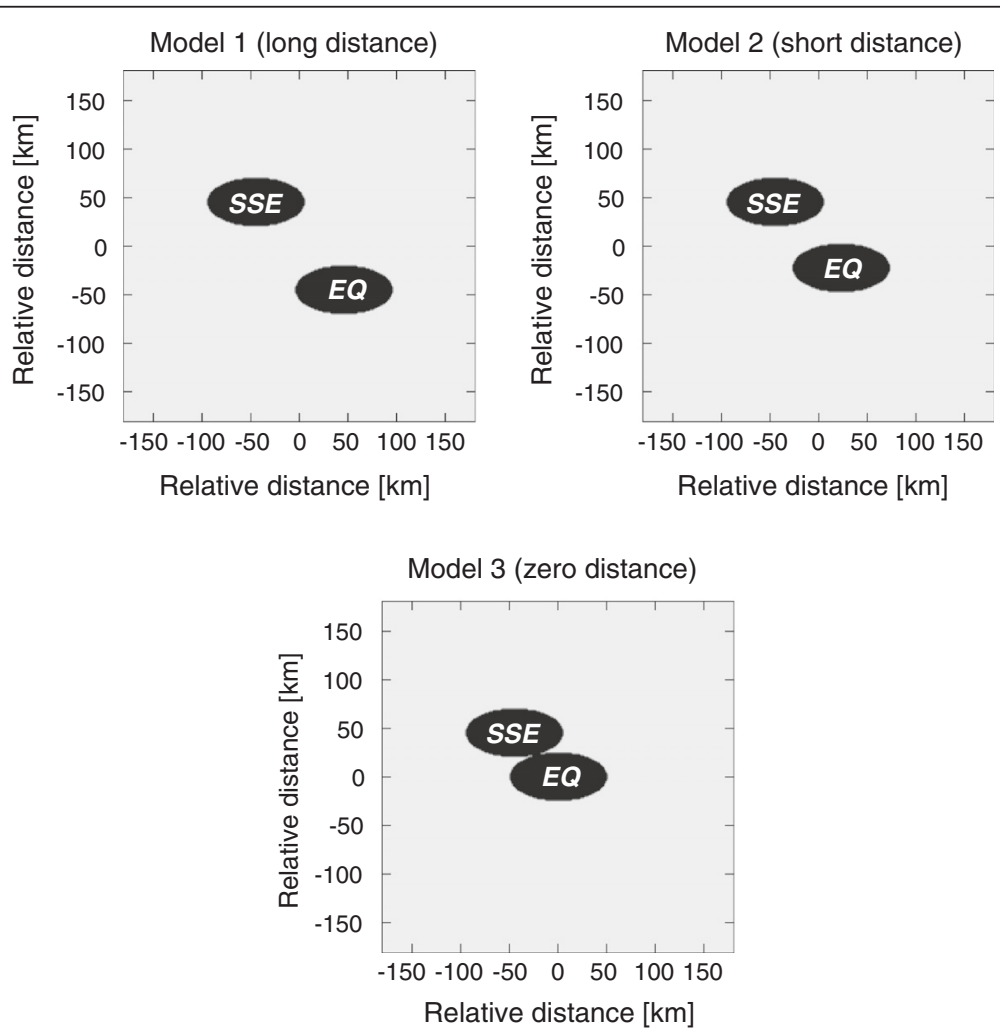

Figure 2 Three fault models with one SSE area, one earthquake (EQ) area, and the other intermediate zone. In terms of the distance between the SSE area and EQ area, model 1 is the long-distance model, model 2 is the short-distance model, and model 3 is the zero-distance model. The locations of the SSE areas are the same in both models. The length of the major axes of the SSE area and EQ area is $100 \mathrm{~km}$ and that of the minor axes is $50 \mathrm{~km}$. The slip direction is the up/down direction in the figures. On the four sides of the faults, we set a steady-slip zone at a width of $22.6 \mathrm{~km}$ for reducing effects of the periodic boundary conditions (e.g., Kato, 2004). 
large slip events are several orders of magnitude different from those estimated in laboratory experiments (see the discussion in Guatteri et al. (2001)). The S-wave velocity $c_{s}$ and the rigidity $G$ are assumed to be $3.5 \mathrm{~km} / \mathrm{s}$ and $34.3 \mathrm{GPa}$, respectively. The plate loading rate $v_{0}$ is $10 \mathrm{~cm} /$ year. The numerical grid size is about $710 \mathrm{~m}$. This value is sufficiently smaller than a critical grid size (e.g., Rice 1993) $\sim G L /(B-A)$, which is approximately $4600 \mathrm{~m}$ for the earthquake area and $18,000 \mathrm{~m}$ for the SSE area. We confirmed that the SSE recurrence interval is about 13 months if we do not set the earthquake area. Here, we define the event recurrence interval as a period between a time when the rising slip velocity reaches the plate loading rate $v_{0}$ and the last time for the same condition. Likewise, the recurrence interval of the earthquake without the SSE area is approximately 310 years.

To investigate the external stress perturbation effect, we test a step-like (static) shear stress change during the interseismic period (e.g., Perfettini et al. 2003; Cho et al. 2009) in additional experiments. The details are described in a later discussion section.

\section{Results}

Figure 3 shows slip velocity evolution at the center of the SSE area and the earthquake area for model 2 (short distance), as an example of the calculation results. The maximal slip velocities of the SSEs are not constant during one interseismic period. It reflects the stress state in the SSE area perturbed by coseismic slip, afterslip, and the early phase of nucleation of the earthquake (e.g., Mitsui and Hirahara 2011). In particular, a latter half of the interseismic period is characterized by the early phase of nucleation.

Figure 4 exhibits temporal evolution of the SSE recurrence intervals during the latter interseismic periods for all the models. First, the results for model 1 (long distance) and model 2 (short distance) are qualitatively similar. The long-term decreasing rate of the SSE intervals in model 1 is approximately 0.004 (month/ year), and that in model 2 is larger but not twice as model 1 ( $\cong 0.006$ (month/year)). Next, the long-term decreasing rate of the SSE intervals in model 3 (zero distance) is nearly 0.015 (month/year), greater than model 1 and model 2, owing to the strongest elastic interaction between the SSE and the earthquake areas. Moreover, during the last decade before the earthquake, the recurrence interval of the SSEs decreases rapidly (about 0.7 (month/ year)). This short-term decrease relates to a late phase of nucleation of the earthquake concentrating a local zone (e.g., Ohnaka 1992). Figure 5 shows the decreasing rates of the SSE recurrence intervals for models 1 to 3 .

Of course, the decreasing rates depend on frictional parameters as well as the distance between the SSE and the earthquake areas. By way of experiment, we change the frictional parameters $A$ and $B$ in the intermediate zone. When we set $A=0.12 \mathrm{MPa}, B=0.045 \mathrm{MPa}$ as a weaker intermediate zone, the long-term decreasing rates gain and reach 0.01 to 0.1 (month/year). In contrast, when we set $A=9 \mathrm{MPa}, B=3 \mathrm{MPa}$ as a stronger intermediate zone, the long-term decrease rates are almost 0 . Weaker intermediate zone, which can be attributed to high pore fluid pressure on a fault, favors larger decreasing rate of the SSE recurrence intervals. Moreover, the size of the SSE and earthquake areas also affects the decreasing rates of the SSE intervals. We checked some cases when the earthquake area is far larger than the SSE area and found that the decreasing rates of the SSE intervals tend to be greater for a larger earthquake area. All the effects of the distance between the SSE and earthquake areas, the weakness of the intermediate zone, and the size of the SSE and earthquake areas reflect the magnitude of the elastic interaction.

\section{Discussion}

Actual interval of SSE recurrence

Our numerical results indicated that the distance between the SSE and the earthquake areas is truly one of the
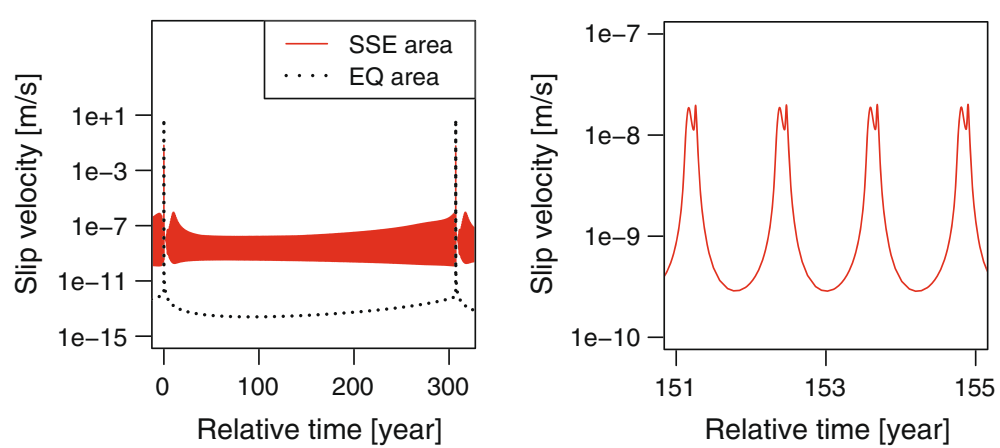

Figure 3 The left figure illustrates slip velocity evolution at the center of the SSE area and the earthquake (EQ) area for model 2. The horizontal axis represents relative time from one earthquake event after several earthquake cycles. The right figure presents an enlarged figure of the slip velocity evolution only at the center of the SSE area. 


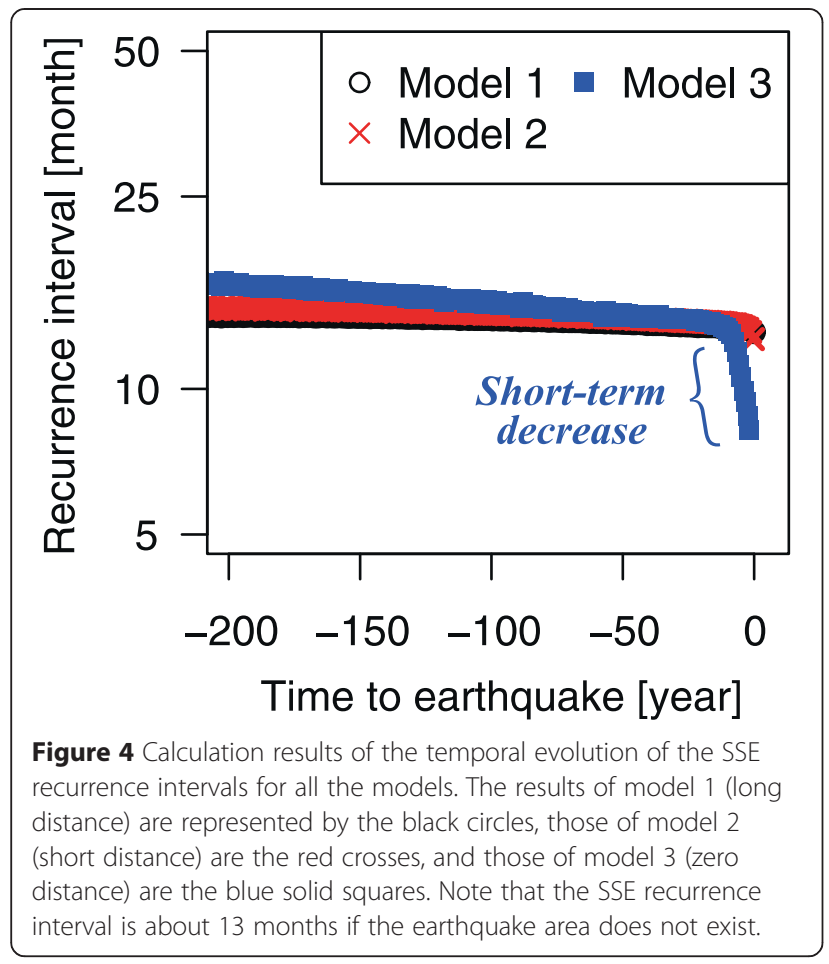

important parameters for the temporal change of the SSE recurrence interval. This fact qualitatively agrees with the observation as was mentioned in the introduction section.

Now, we analyze the actual SSE recurrence intervals. Referring to the previous studies (Hirose et al. 2012;

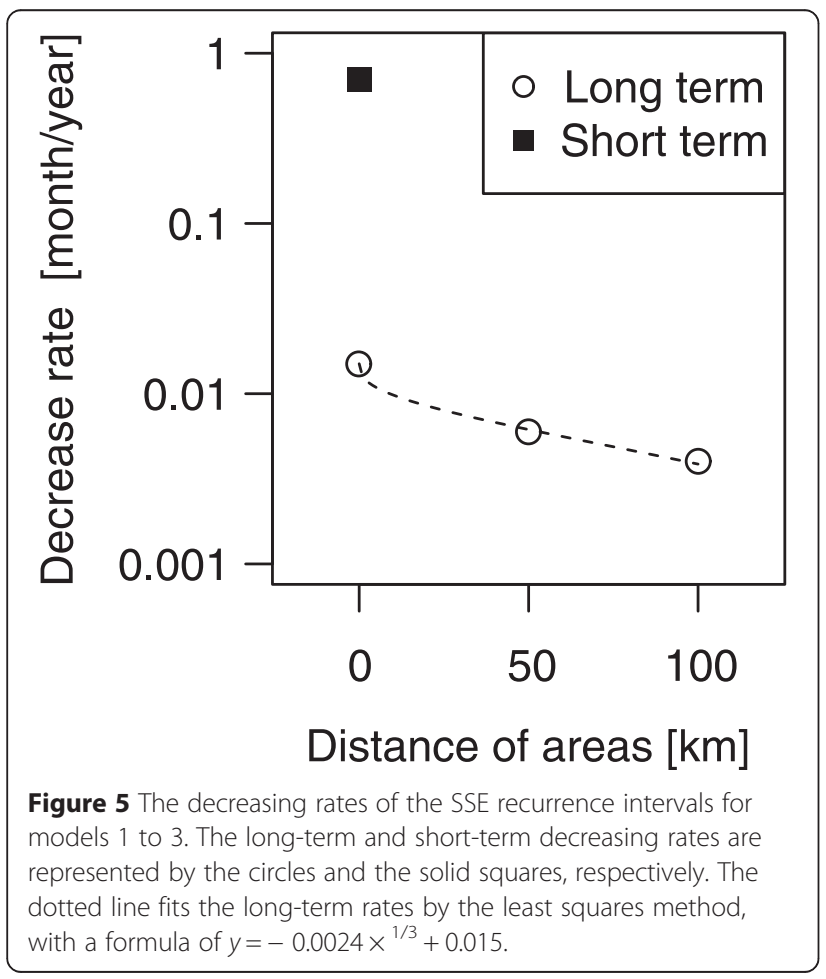

Ozawa 2014; Kato et al. 2014; Szeliga et al. 2008; Pacific Northwest Seismic Network 2014; Heki and Kataoka 2008; Heki, personal communication), we compile the occurrence times of the SSEs at the three subduction zones. Table 1 shows them. We present the temporal evolution of the SSE recurrence intervals by Figure 6 .

In order to extract the trends, we fit the data by the least squares method using the linear function (black broken line). The slope of the regression line of the Boso zone is $-2.90( \pm 0.80)$ (month/year), where the error range represents the standard error of estimate. The slopes of the $n$. Cascadia zone and the Yaeyama zone are $-0.12( \pm 0.10)$ (month/year) and $-0.04( \pm 0.08)$ (month/year), respectively. We find that the SSE recurrence intervals tend to be shorter in all the zones, although the data on the SSE recurrence intervals may not be sufficient yet to discuss this point. The degree of the data variation implies that the long-term decreases of the SSE recurrence intervals, which are far milder than the short-term decreases, are not observable in natural phenomena.

\section{External stress perturbation effects on SSE activity}

The observed large decreasing rate of the SSE recurrence intervals at the Boso zone might truly result from the nucleation process of the neighboring earthquake, however, the effect of the 2011 Tohoku earthquake should not be ignored. The Mw 9.0 Tohoku earthquake and its afterslip caused a non-negligible Coulomb stress change (e.g., King et al. 1994) at most 0.1 MPa (Hirose et al. 2012), although the epicenter of the Tohoku

Table 1 The occurrence times of the SSEs at the three subduction zones

\begin{tabular}{lll}
\hline N. Cascadia $^{\text {a }}$ & Yaeyama $^{\text {b }}$ & Boso $^{\text {c }}$ \\
\hline April 1997 & September 1997, June 1998 & May 1983 \\
July 1998 & February 1999, September 1999 & December 1990 \\
August 1999 & March 2000, October 2000 & May 1996 \\
December 2000 & March 2001, October 2001 & October 2002 \\
February 2002 & March 2002, September 2002 & August 2007 \\
February 2003 & April 2003, October 2003 & March 2011 \\
July 2004 & April 2004, November 2004 & October 2011 \\
September 2005 & May 2005, August 2005 & January 2014 \\
January 2007 & January 2006, July 2006 & \\
May 2008 & January 2007, February 2007 & \\
May 2009 & October 2007, May 2008 & \\
August 2010 & November 2008, July 2009 & \\
July 2011 & December 2009, July 2010 & \\
September 2012 & February 2011, October 2011 & \\
September 2013 & April 2012 & \\
\hline Szeliga at (2008) & \\
\hline
\end{tabular}

${ }^{\mathrm{a}}$ Szeliga et al. (2008) and the continuous monitoring by Pacific Northwest Seismic Network (2014). ${ }^{b}$ Heki (personal communication) following Heki and Kataoka (2008). 'Hirose et al. (2012), Ozawa (2014), and Kato et al. (2014). 

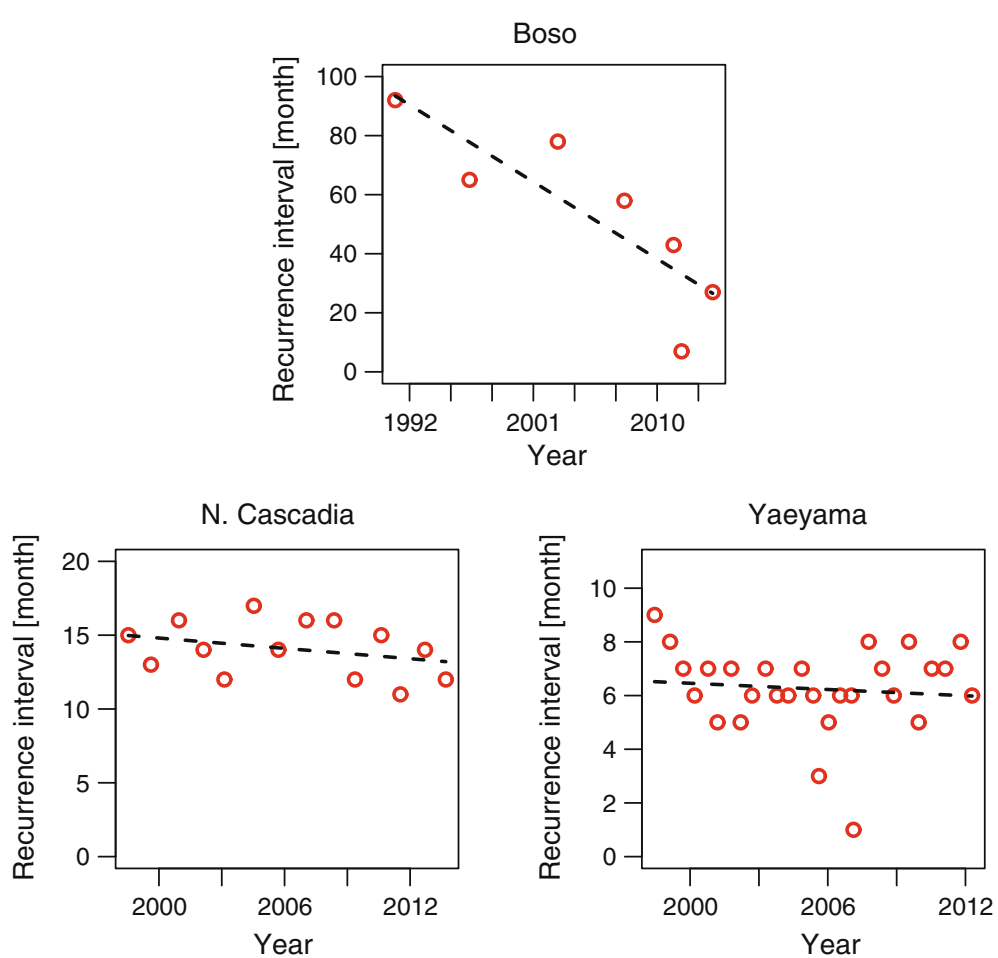

Figure 6 Temporal evolution of the recurrence interval of the SSES at the three subduction zone. Red circle indicates each occurrence of the SSE and elapsed time from the previous event. The black broken line illustrates fitted lines using the linear function. The slopes of the all fitted lines are negative: $-2.90( \pm 0.80)$ (month/year) for the Boso zone, $-0.12( \pm 0.10)$ (month/year) for the northern Cascadia zone, and $-0.04( \pm 0.08)$ (month/year) for the Yaeyama zone.

earthquake $\left(142.9^{\circ} \mathrm{E},-38.1^{\circ} \mathrm{N}\right)$ was about $400 \mathrm{~km}$ far from the Boso SSE zone.

In order to check the degree of such an external stress perturbation effect, we perform another experiment. We add a step-like (static) shear stress change on the whole fault, alternative to the Coulomb stress change, as large as $0.1 \mathrm{MPa}$ during the interseismic period for model 3 .
Figure 7 shows an example of the calculation results. The shear stress is loaded around 150 years before the earthquake occurrence in the no-stressed case. An SSE is triggered instantaneously after the stress load, and the following SSE activity seems strongly fluctuated. The SSE recurrence interval has the largest value immediately after the instantaneous triggering of the SSE, and
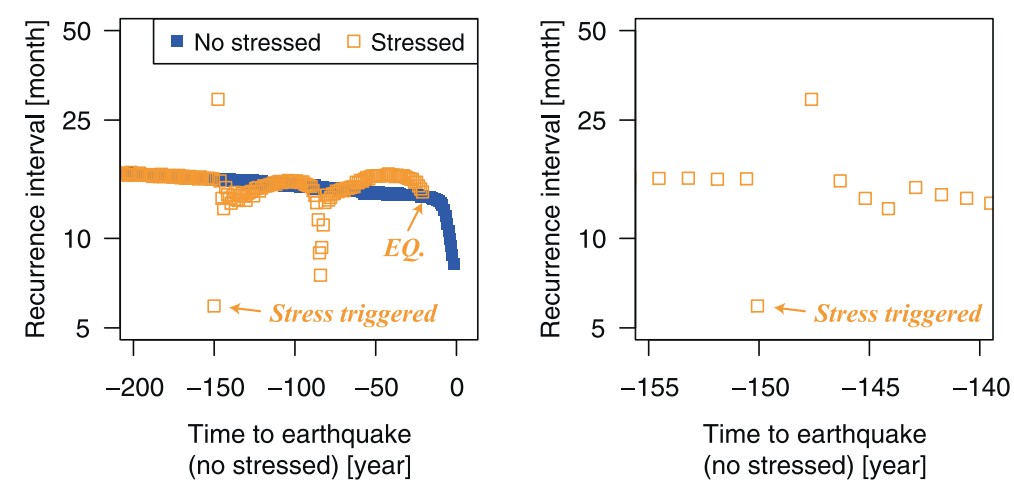

Figure 7 Calculation results of the temporal evolution of the SSE recurrence intervals for model 3. In the left figure, 'No-stressed' case (blue solid squares) is the same result as that in Figure 4. In 'stressed' case (orange squares), the shear stress as large as $0.1 \mathrm{MPa}$ is loaded around -150 years in the original horizontal axis. The right figure exhibits the enlarged figure of the recurrence interval evolution around the stressing time. 


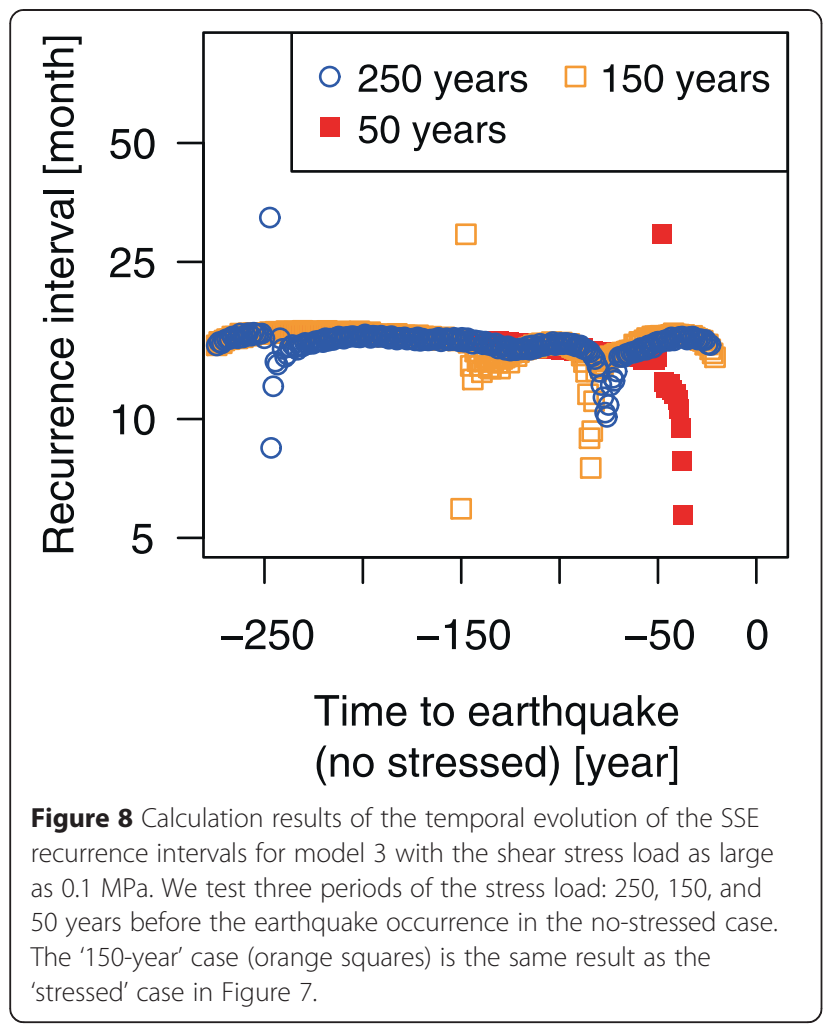

then, the rapid shortening of the SSE intervals occur. The rapid shortening also occurs after many decades. Such fault behavior arises from a large deviation from (semi) limit-cycle behavior of the frictional system. The earthquake occurrence is also affected, namely, the added shear stress advances the next earthquake.

Figure 8 also presents the external stress perturbation effect. We test three periods for the stress load: 250, 150, and 50 years before the earthquake occurrence in the no-stressed case. Both the 250-year and 150-year cases reveal that the effects of the external stress perturbation continue disturbing the evolution of the SSE recurrence intervals. It is noteworthy that the rapid shortenings of the SSE recurrence intervals occur without the following large earthquakes in both cases. By contrast, the rapid shortening of the SSE recurrence intervals in the 50-year case is immediately followed by the earthquake. This difference can be attributed to the frictional state of the earthquake area. In the former cases, the stress loads $(0.1 \mathrm{MPa})$ do not directly trigger the earthquake but strongly fluctuate the SSE activity, whose stress drops are on the order of several tens $\mathrm{kPa}$. In the latter case, the stress load $(0.1 \mathrm{MPa})$ directly leads to the (delayed) earthquake triggering because the earthquake nucleation progressed sufficiently.

We found that the shortening of the SSE recurrence intervals by the external stress perturbation can be as rapid as the short-term decrease by the earthquake nucleation (Figures 7 and 8). We also found that the external stress perturbation easily hide the long-term decreasing rate. The stress perturbation effect may appear in the rapid decrease of the SSE recurrence intervals at the Yaeyama zone around 2005 to 2007 (see Figure 6). It might be related to afterslip of the M7-class 2002 Hualien earthquake (Nakamura 2009b) which occurred on the east coast of Taiwan and on the west side of the SSE zone, or magma injection in the back-arc Okinawa Trough (Tu and Heki 2014).

In the case of the Boso SSE, the recurrence intervals was actually decreasing (Figure 6), which might correspond to the nucleation of the adjoining large earthquake, but that after the 2011 Tohoku earthquake should be strongly affected by the external stress perturbation. This fact suggests that the current frictional state at the Boso SSE zone is complicated. In terms of the development of earthquake seismology, it is necessary to monitor the crustal deformation continuously until the future occurrence of the adjoining large earthquake.

\section{Conclusion}

We investigated interval modulation of SSEs by two types of earthquake loading: effects of nucleation and external stress perturbation. We confirmed that SSE recurrence intervals tend to be shorter owing to a nucleation process of a nearby large earthquake, based on the numerical modeling with the frictional system. The decreasing rate of the SSE intervals depends on magnitude of the elastic interaction. One important point is the distance between the SSE and earthquake areas. When the distance between the SSE and earthquake areas is nearly zero with the same size of the SSE and earthquake areas, the short-term further decrease in the SSE recurrence intervals occurs just before the earthquake occurrence. Only the short-term decrease can be as significant as the fluctuation of the SSE recurrence intervals by external stress perturbation. The effect of the external stress perturbation on the SSE recurrence intervals continues until the occurrence of the adjacent earthquake.

\section{Competing interests}

The author declares that he has no competing interests.

\section{Author's contributions}

YM analyzed the SSE recurrence data, performed the numerical experiments, and wrote the paper. The author read and approved the final manuscript.

\section{Acknowledgements}

YM thanks Kosuke Heki for discussing and providing the data. Incisive comments by two anonymous reviewers improved the manuscript. We use Generic Mapping Tools (Wessel and Smith 1995) to draw the maps. 
Received: 2 January 2015 Accepted: 15 April 2015

Published online: 25 April 2015

\section{References}

Ando M (1971) A fault-origin model of the great Kanto earthquake of 1923 as deduced from geodetic data. Bull Earthquake Res Inst Univ Tokyo 49:19-32

Ariyoshi K, Hori T, Ampuero J-P, Kaneda Y, Matsuzawa T, Hino R, Hasegawa A (2009) Influence of interaction between small asperities on various types of slow earthquakes in a 3-D simulation for a subduction plate boundary. Gond Res 16:534-544

Atwater BF (1987) Evidence for great Holocene earthquakes along the outer coast of Washington state. Science 236:942-944

Bird P (2003) An updated digital model of plate boundaries. Geochem Geophys Geosys 4:1027

Cho I, Tada T, Kuwahara Y (2009) Stress triggering of large earthquakes complicated by transient aseismic slip episodes. J Geophys Res 114:B07310

DeMets C, Gordon RG, Argus DF, Stein S (1990) Current plate motions. Geophys J Int 101:425-478

Dieterich JH (1979) Modeling of rock friction: 1. experimental results and constitutive equations. J Geophys Res 84:2161-2168

Dragert H, Wang K, James TS (2001) A silent slip event on the deeper Cascadia subduction interface. Science 292:1525-1528

Dragert H, Wang K, Rogers G (2004) Geodetic and seismic signatures of episodic tremor and slip in the northern Cascadia subduction zone. Earth Planets space 56:1143-1150

Guatteri M, Spudich P, Beroza GC (2001) Inferring rate and state friction parameters from a rupture model of the 1995 Hyogo-ken Nanbu (Kobe) Japan earthquake. J Geophys Res 106:26511-26521

Heki K, Kataoka T (2008) On the biannually repeating slow-slip events at the Ryukyu Trench, southwestern Japan. J Geophys Res 113:B11402

Heki K, Mitsui Y (2013) Accelerated pacific plate subduction following interplate thrust earthquakes at the Japan trench. Earth Planet Sci Lett 363:44-49

Hirose H, Hirahara K, Kimata F, Fujii N, Miyazaki S (1999) A slow thrust slip event following the 1996 Hyuganada earthquakes beneath the Bungo Channel, southwest Japan. Geophys Res Lett 26:3237-3240

Hirose H, Kimura H, Enescu B, Aoi S (2012) Recurrent slow slip event likely hastened by the 2011 Tohoku earthquake. Proc Natl Acad Sci U S A 109:15157-15161

Kato N (2003) Repeating slip events at a circular asperity: numerical simulation with a rate- and state-dependent friction law. Bull Earthquake Res Inst Univ Tokyo 78:151-166

Kato N (2004) Interaction of slip on asperities: numerical simulation of seismic cycles on a two-dimensional planar fault with nonuniform frictional property. J Geophys Res 109:B12306

Kato A, Igarashi T, Obara K (2014) Detection of a hidden Boso slow slip event immediately after the 2011 Mw 9.0 Tohoku-Oki earthquake, Japan. Geophys Res Lett 41:5868-5874

King GCP, Stein RS, Lin J (1994) Static stress changes and the triggering of earthquakes. Bull Seis Soc Am 84:935-953

Leonard LJ, Currie CA, Mazzotti S, Hyndman RD (2010) Rupture area and displacement of past Cascadia great earthquakes from coastal coseismic subsidence. GSA Bull 122:1951-1968

Linde AT, Gladwin MT, Johnston MJS, Gwyther RL, Bilham RG (1996) A slow earthquake sequence on the San Andreas fault. Nature 383:65-68

Matsuzawa T, Hirose H, Shibazaki B, Obara K (2010) Modeling short- and long-term slow slip events in the seismic cycles of large subduction earthquakes. J Geophys Res 115:B12301

Mitsui Y, Hirahara K (2009) Coseismic thermal pressurization can notably prolong earthquake recurrence intervals on weak rate and state friction faults: numerical experiments using different constitutive equations. J Geophys Res 114:B09304

Mitsui Y, Hirahara K (2011) Fault instability on a finite and planar fault related to early phase of nucleation. J Geophys Res 116:B06301

Nakamura M (2009a) Fault model of the 1771 Yaeyama earthquake along the Ryukyu Trench estimated from the devastating tsunami. Geophys Res Lett 36:L19307

Nakamura M (2009b) Aseismic crustal movement in southern Ryukyu Trench, southwest Japan. Geophys Res Lett 36:L20312

Ohnaka M (1992) Earthquake source nucleation: a physical model for short-term precursors. Tectonophysics 1-4:149-178
Ozawa S (2014) Shortening of recurrence interval of Boso slow slip events in Japan. Geophys Res Lett 41:2762-2768

Ozawa S, Miyazaki S, Hatanaka Y, Imakiire T, Kaidzu M, Murakami M (2003) Characteristic silent earthquakes in the eastern part of the Boso peninsula, Central Japan. Geophys Res Lett 30:6

Pacific Northwest Seismic Network, Slow slip and tremor observations and research at the PNSN. http://www.pnsn.org/tremor/overview Accessed 1 November 2014

Perfettini H, Schmittbuhl J, Cochard A (2003) Shear and normal load perturbations on a two-dimensional continuous fault: 1. static triggering. J Geophys Res 108:B9

Rice JR (1993) Spatio-temporal complexity of slip on a fault. J Geophys Res 98:9885-9907

Rogers G, Dragert H (2003) Episodic tremor and slip on the Cascadia subduction zone: the chatter of silent slip. Science 300:1942-1943

Ruina A (1983) Slip instability and state variable friction laws. J Geophys Res 88:10359-10370

Szeliga W, Melbourne T, Santillan M, Miller M (2008) GPS constraints on 34 slow slip events within the Cascadia subduction zone, 1997-2005. Geophys Res Lett 113:B04404

Tse ST, Rice JR (1986) Crustal earthquake instability in relation to the depth variation of frictional slip properties. J Geophys Res 91:9452-9472

Tu Y, Heki K (2014) The variations of long time period slow slip events along the Ryukyu subduction zone. Paper presented at the 2014 American Geophysical Union Fall meetings, San Francisco, pp 15-19

Wessel P, Smith WHF (1995) New version of the generic mapping tools released. Eos Trans AGU 76:329

\section{Submit your manuscript to a SpringerOpen ${ }^{\circ}$ journal and benefit from:}

- Convenient online submission

- Rigorous peer review

- Immediate publication on acceptance

- Open access: articles freely available online

- High visibility within the field

- Retaining the copyright to your article

Submit your next manuscript at $>$ springeropen.com 